\title{
Romania, Slovakia and Hungary: evolution of mutual funds in recent years
}

\author{
Luminița NICOLESCU \\ The Bucharest University of Economic Studies, Bucharest, Romania \\ luminicolescu@yahoo.com \\ Florentin Gabriel TUDORACHE \\ The Bucharest University of Economic Studies, Bucharest, Romania \\ gabriel_tud@yahoo.com
}

\begin{abstract}
Mutual funds and their evolution represent an expression of the performances of capital markets in the majority of states. The inflows and the outflows in mutual funds are used to evaluate the achievements obtained in capital markets all over the world. At the same time, both individual and organizational investors guide their acquisition decisions on information about past accomplishments of the various mutual funds and invest in funds that registered good and very good performances in the past, while trying to give up less performing funds. However, the decision is usually asymmetrical, as investors rather take into consideration the very good past performances of mutual funds and prefer to invest in those, while the pace of giving up to less performing funds is not accordingly prominent. Investors' behaviour can differ from one country to another and the behaviour of those originating from developed countries and more mature capital markets have been studied to a higher extent internationally, while developing capital markets have been less studied so far. The present paper looks at capital markets from the perspective of mutual funds in three (rather) emerging capital markets located in Central and Eastern Europe, namely: Romania, Slovakia and Hungary. The inflows and outflows in mutual funds are analyzed for the 2007-2014 period and based on that, the investors' behaviour in the three countries is looked at. The analysis has both a dynamic and a comparative character with the purpose to identify similarities and differences between the three analyzed countries, as well as to identify how they compare with more mature financial and capital markets. The analysis also tries to distinguish specific features of both evolution of mutual funds and investors' behaviour, in a period that comprised two different stages of the economic cycle: financial crisis and the debut of the economic recovery period.
\end{abstract}

Keywords: open ended funds, Central and Eastern Europe, investment behaviour, Romania, Slovakia, Hungary.

\section{Introduction}

A common indicator to evaluate the financial markets performance in different countries is seen to be the evolution of mutual funds as far as their inflows and outflows are concerned. The performance of mutual funds in the past is one of the main criteria for investment decision. Most mutual funds studies conducted till now envisaged mainly developed markets, especially the US market, and there are very few studies looking at emerging financial markets, even though in recent years the mutual funds industry grew in those markets, especially in the markets from Central and Eastern Europe. The present study 
makes a contribution to the literature by analysing and depicting the evolution of mutual funds in emerging markets from this region, namely Romania, Slovakia and Hungary.

The research envisaged the study of flows of financial resources in and out of mutual funds from the three countries during the period 2007-2014 and to analyse how investors from these countries behave in terms of investments in mutual funds.

The paper is organized as follows: section two presents literature references related to the flow-performance relationship and other similar aspects, section three depicts the research methodology used for all countries, section four illustrates the main research findings in a comparative manner and the final section, the conclusions summarize the findings and emphasize on what is similar and what is different in the three countries.

\section{Literature review}

Financial markets play important roles in national economies, as well as at international level. The use of financial markets to gather the necessary resources for companies' financing is already common worldwide. Capital markets and not only are used for investment financing and investment can be done directly or by collective investment. Investing in mutual funds is one form of collective investment that brings numerous advantages to individual investors as acknowledged in the literature. Alexakis et al. (2004) include among those advantages the following: the assets management costs are lower, decisions and choices are done by professionals and investment portfolio is diversified. Bodie et al. (2005) also posit that investments in funds allow for avoiding or diminishing losses when individual companies fail, by compensating with the gains of other individual companies, mainly due to portfolio diversification. The professional management used by investment funds determine for individual investors more stable returns compared to the situation in which they would make investment decisions on their own (Chatfield-Roberts, 2006).

The way how investors make the decision to invest is a relevant subject for both practitioners and theoreticians. There are different criteria that consist the bases of investors' decision, among which performance is probably the most important and the most used by investors.

There is a vast body of literature that agrees on the influence of past performance of funds on the fund flows (Patel, Zeckhauser and Hendricks, 1991; Ippolito, 1992; Grinblatt and Titman, 1992; Goetzmann, 1994; Alexakis et al., 2004 and Cha and Kim, 2007).

Reality showed that usually money inflows in mutual funds chase high performance obtained in the past and money outflows are associated with poor performance in the past (Cha and Kim, 2007). An immediate consequence would be that money will flow towards the funds that registered high returns in the previous periods, such as the previous year. Also it is expected that funds that underperform will register money outflows. Experience illustrated that this is not always the case. Barber and Odean (2000) found that investors are reluctant to sell the fund units with poor performance, mainly due to the losses associated to the process. This behaviour is associated with what is known in the literature as the flow-performance convexity. A relationship between flows and performance that is convex is encountered when flows depend to a large extent on past performance, but 
investors look for the most performant funds extensively, while they pay less attention to selling the poorly performing funds (Fu et al, 2012).

The phenomenon is largely encountered, but it manifests differently with various intensity levels in different circumstances. Authors such as Ferreira et al. (2012) found that flowperformance convexity is much higher in less developed countries in comparison with developed countries. A possible explanation can be related to the level of maturity and financial knowledge that investors have, aspects that are less pronounced in less developed countries.

Besides past fund performance the literature (Sirri and Tufano, 1998; Fu, Navone, Pagani and Pantos, 2012; Tudorache et al., 2015) acknowledges that there are some other factors that are taken into consideration when an investment decision is made. They include external factors such as: administration fees, perceived risks, cost of search and marketing fees and media attention, as well as internal factors such as the degree of risk aversion and the level of financial knowledge of investors. The level of information of investors can be also be influenced by advertising activities that are usually conducted for funds that $r$ outperformed in recent previous periods (Ferreira, Keswani, Miguel and Ramos, 2012) or by alternative communication modes, such as word of mouth (Andrei, Zaiţ, Vătămănescu and Pînzaru, 2017).

The flow of money that comes into mutual funds was a subject of interest for many authors who studied the capital markets, either to illustrate the evolution of markets or to study the investors' behaviour (Ferreira, Keswani, Miguel \& Ramos, 2012; Sapp \& Tiwari, 2004; Ivkovic \& Weisbenner, 2009). Numerous studies focused on the US equity market (Kim, 2013; Fu, Navone, Pagani \& Pantos, 2012; Li Ma, 2013). Other studies looked at other countries: developed countries (Ferreira et al. 2012) or developing countries (Varga \& Wengert, 2010; Varga, 2011). Among the developing markets, the mutual market in Brazil was studied by Varga and Wengert (2010) and Varga (2011), while Ferreira, Keswani, Miguel and Ramos (2012) studied 28 countries including emerging capital markets (India, Indonesia, Malaysia, Poland, Taiwan, Thailand). In Central and Eastern Europe, the mutual funds market in Romania was studied by Tudorache, Nicolescu and Lupu (2015) and the mutual funds market in Hungary was analyzed by Tudorache and Nicolescu (2016), while Dima and Vasilache (2013) approach in their study the context of social responsibility .

The present study tries to complete the existing literature by analyzing mutual funds evolutions and investors' behaviour for three markets in the region of Central and Eastern Europe.

\section{Methodology}

The present paper analysed the evolution of mutual funds, specifically open-ended funds that operate in three emerging financial markets from Central and Eastern Europe: from Romania, Slovakia and Hungary. Data collected envisaged to measure the performance of mutual funds in these countries. Performance was assessed by looking at the unit value of each fund and the returns obtained and at the dimension of the funds, evaluated based on their net assets.

The data on mutual funds was drawn from sites of the Funds' Managers Association from the three countries, respectively: from AAF (The Fund Managers' Association from 
Romania) ${ }^{1}$, from SASS (The Fund Managers' Association from Slovakia) ${ }^{2}$ for Slovakia and the BAMOSZ (The Fund Managers' Association from Hungary) ${ }^{3}$ for Hungary. The number of members in these associations differ from one country to another as follows: AAF has 21 investments management companies as members who administer 105 funds; SASS has 21 investment management companies as members who administer over 500 mutual funds, while BAMOZ has 23 investment management companies as members who administer 581 mutual funds.

The period for data collection was January 2007 to December 2014 and data collected included information on all the investment funds marketed in the three capital markets, being excepted funds marketed in those national markets, but managed by foreign societies. Data gathered about both fund unit value and the total net assets was collected on a monthly basis. The study retained for analysis only those funds for which there were at least 12 monthly observations. Data about the total of 975 mutual funds included in the analysis in the three countries was grouped in five categories of mutual funds for each country as they are presented in Table no. 1.

Romania has the lowest number of open ended mutual funds (76), while Slovakia has the highest number of mutual funds (505), having us thinking from the very beginning that there are differences in the level of development of the financial markets in the studied countries.

Table no. 1. Categories of mutual funds included in the study, 2007-2014

\begin{tabular}{|r|r|r|r|r|r|r|}
\hline $\begin{array}{r}\text { Categories } \\
\text { of funds }\end{array}$ & $\begin{array}{r}\text { Equity } \\
\text { funds }\end{array}$ & Mixed funds & Other funds & $\begin{array}{r}\text { Monetary } \\
\text { funds }\end{array}$ & Bond funds & Total \\
\hline Romania & 15 & 27 & 19 & 5 & 10 & 76 \\
\hline Slovakia & 224 & 44 & 113 & 35 & 89 & 505 \\
\hline Hungary & 126 & 45 & 125 & 46 & 52 & 394 \\
\hline Total & 365 & 116 & 257 & 86 & 151 & 975 \\
\hline
\end{tabular}

Source: Authors' own research; AAF Romania; SASS Slovakia; BAMOSZ Hungary

The evolution of the five categories of mutual funds was characterized by computing and analysing the four moments of the time series of returns for the period 2007-2014: the mean returns, the standard deviation of returns, the skewness and the kurtosis.

\section{Results and discussions}

This section presents the main findings of the research, organized according to the above described methodology.

\section{Mean returns}

Investors guide themselves on the previous performance of funds, when deciding to acquire new units of funds and in this context the analysis of mean returns of mutual funds becomes an important indicator for the funds' performance. At the same time, mutual funds

\footnotetext{
${ }^{1}$ AAF (Fund Managers' Association from Romania), www.aaf.ro, retrieved May 2015.

${ }^{2}$ SASS (The Fund Managers' Association from Slovakia), http://www.ass.sk/, retrieved May 2015.

${ }^{3}$ BAMOSZ (The Fund Managers' Association from Hungary), http://www.bamosz.hu/, retrieved May 2015.
} 
in each country (that also have in their composition stocks) are compared with the market index (the index of the Stock Exchange in each country), in order to compare performance of mutual funds with the performance of the market and to identify if they have better results than the equity market, if it is more beneficial for investors to acquire fund units in mutual funds or to invest directly to the Stock Exchange.

Figures no. $1 \mathrm{a}, 1 \mathrm{~b}$ and $1 \mathrm{c}$ reveal that the mean returns of mutual funds differ from one country to another and from one fund category to another, presenting interesting features. The high risk fund categories (equity funds, other funds and mixed funds) had similar evolutions of the mean returns in the three countries, with the equity funds having negative monthly mean returns and the other two fund categories having positive monthly mean returns. To exemplify we will look at the equity funds category in the three countries.

In Romania, the equity funds had mainly negative mean returns in the studied period, but the results of the equity funds were better that the ones obtained by BET (the Bucharest Stock Exchange Index): the median of the mean returns of equity funds was ($0,002)$, while the median of mean returns of BET was $(-0,0072)$. This suggests higher risks of investing directly to the stock exchange than investing in equity mutual funds in Romania, as the stock exchange had lower performance.

In Slovakia, the equity funds category had also a negative value $(-0,00044)$ of the median of mean returns, illustrating poor performance on overall, however this was higher than the median of mean returns from SAX (the Bratislava Stock Exchange Index) $(-0,067)$, illustrating better results of mutual funds than the stock exchange. In spite of the overall weak results of this fund category, half of the funds in the category had positive mean returns in the studied period and the funds that recorded the highest mean returns (six funds) among all funds categories come from this fund category.

In Hungary, the median of the mean returns of the equity funds category has a negative value $(-0,0003)$ and is close to the median of the mean returns of BUX in the analyzed period $(-0,0018)$.

The best results as far as the mean returns of equity funds are concerned, have been registered in Hungary $(-0,026 \%$ monthly average returns) while in Romania there were encountered the lowest mean returns $(-0,02 \%$ monthly).

The fact that in the three countries the results of the equity funds were rather similar to the results obtained at the national stock exchanges is an expected result, considering the fact that this fund category comprises to a large extent shares that are traded on the stock exchange. In all countries the range of the mean returns was the highest for the equity funds in all five categories, illustrating once again the high risk associated with the equity funds category. 


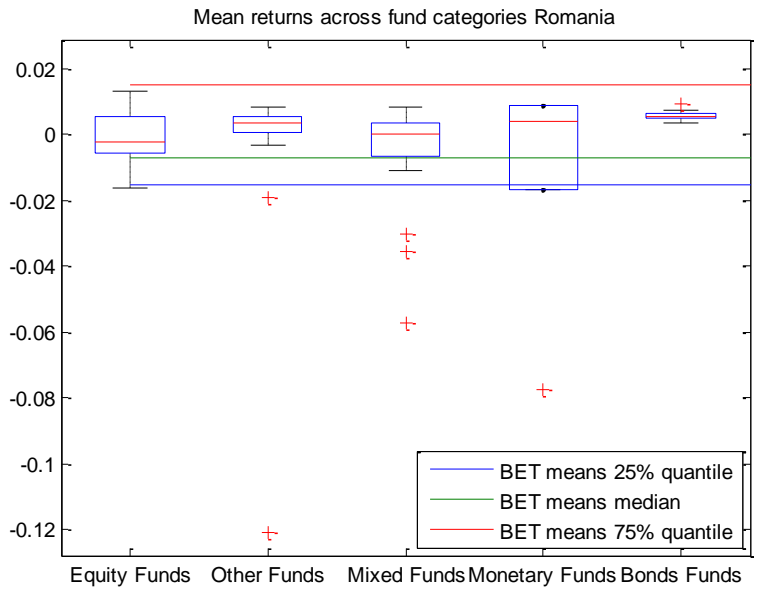

PICBE | 700
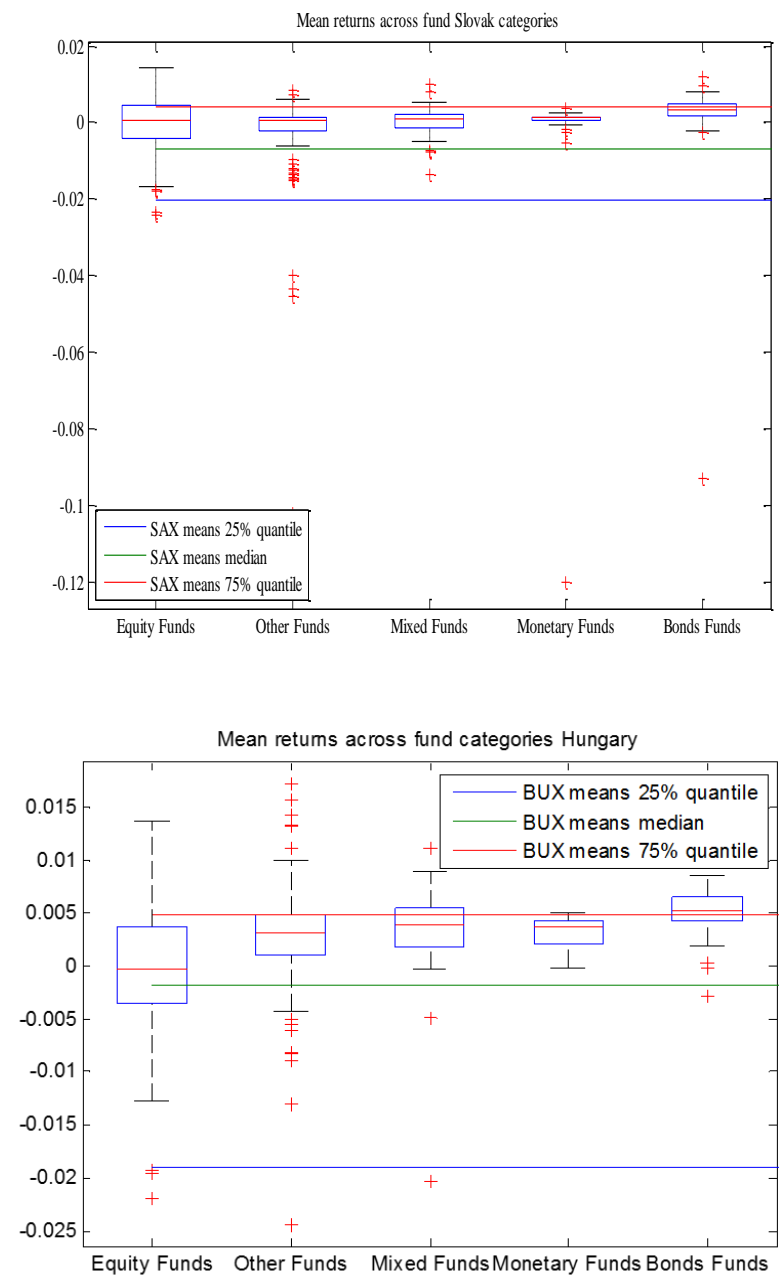

Figure 1. Mean returns for mutual funds in Romania (1a), Slovakia (1b) and Hungary (1c) Source: Authors' research

DOI: 10.2478/picbe-2018-0062, pp. 695-710, ISSN 2558-9652| Proceedings of the $12^{\text {th }}$ International Conference on Business Excellence 2018 
The low risk fund categories had better overall results for the mean returns as compared to the high risk funds category in all three countries. In Romania, the bond funds category had the best results in terms of mean returns, all having positive values and the smallest spread of all fund categories. A similar situation was encountered in Hungary, where the bond funds category had the best mean returns in the market among all five fund categories. In Slovakia, bond funds had also better results than monetary funds in terms of mean returns, but higher spread (higher associated risk).

It can be noticed that as far as the mutual funds' performance measured as mean returns, there were both similarities and differences among the three countries: overall evolutions and trends were rather similar on funds' categories, while the actual monthly mean returns were quite different.

\section{Standard deviation}

The standard deviation of the mean returns of the mutual funds expresses the risks associated with each category of funds. The lower the standard deviation of returns, the lower the risks associated to those funds and the higher the standard deviations, the higher the risks associated with those funds.

In all three countries, the medians of the standard deviations of mean returns had higher values for the high risk fund categories as compared to the low risk fund categories, as presented in figure 2. In Romania, Slovakia and Hungary the equity funds had the highest standard deviations, implying the highest risks in all fund categories. In Romania equity funds did not have values outside the whiskers, illustrating that there are no funds with extreme risks in this category.

In all three countries the other two categories of high risk funds (other funds and mixed funds) had smaller standard deviations than equity funds presenting on average lower risk than those, but on the other hand some of them presented extreme risks, having values outside the boxplots ( 15 out of 113 other funds in Slovakia; 2 out of 125 other funds in Hungary). However, these two funds categories had lower values of standard deviations in all three countries in comparison with the national Stock Exchange indexes, showing that is better to invest in mutual funds than directly to the Stock Exchange.

Lower risk fund categories (bond funds and monetary funds) had medians of standard deviations lower than those in the high risk categories in all countries, depicting an expected behaviour of these funds categories in all three markets. In Romania, Slovakia and Hungary the monetary funds had the lowest risk in all funds categories with the lowest medians of the standard deviations $(0,0029 ; 0,0038$ and 0,0018$)$. An atypical situation was encountered in Hungary, where in the bond fund category there were two funds with values of standard deviations overpassing the boxplot and illustrating higher risks. 


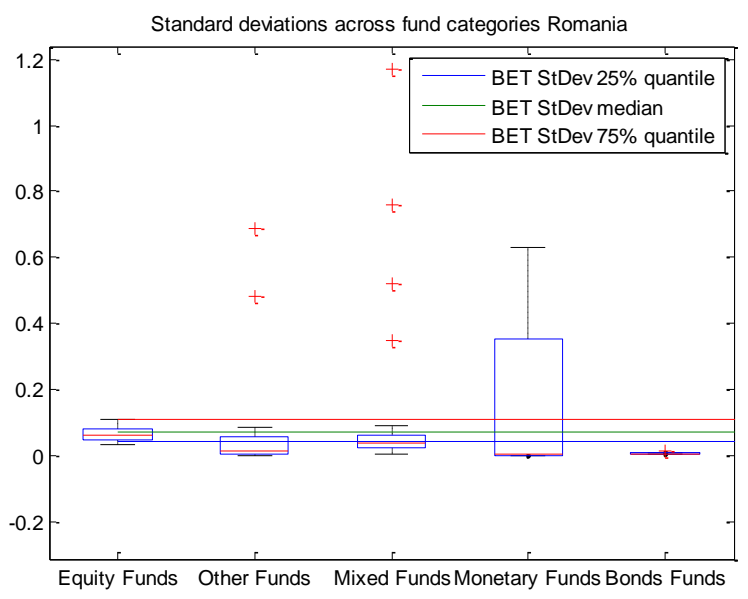

PICBE | 702
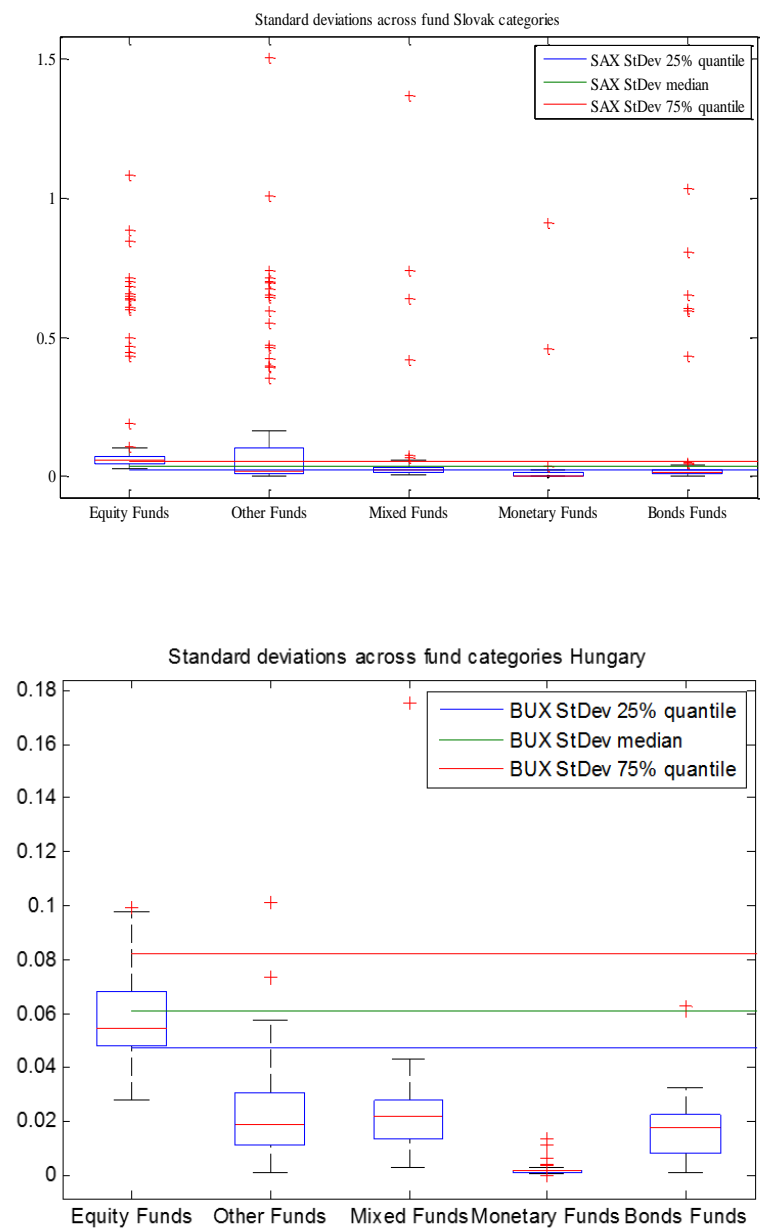

Figure 2. Standard deviations of returns for mutual funds in Romania (2a), Slovakia (2b) and Hungary (2c)

Source: Authors' research

DOI: $10.2478 /$ picbe-2018-0062, pp. 695-710, ISSN 2558-9652| Proceedings of the $12^{\text {th }}$ International Conference on Business Excellence 2018 


\section{Skewness}

The Skewness coefficient of asymmetry (known also as the third grade derivative or the third moment) illustrates the frequency with which returns are concentrated in one direction or another of the distribution, concentrated to the right or to the left of the distribution. In the case of the normal distribution of returns the skewness coefficient is zero. For skewness coefficients that are positive, we have a right skewed distribution, the distribution is inclined to the left and most values are concentrated to the left of the mean, the distribution has long tails to the right and depicts a high probability of having extreme values situated in the right side of the distribution. For skewness coefficients that are negative, we have a left skewed distribution, the distribution is inclined to the right and most values are concentrated to the right of the mean, the distribution has long tails to the left and depicts the risk of having extreme negative values to the left side of the distribution. Usually investors prefer to invest in companies or funds that are positively skewed to the right and have long tails to the right.

In Slovakia, all fund categories presented negative values of skewness in the studied period illustrating high risks of having negative extreme values of the returns of the mutual funds. Equity funds had negative values of skewness in all three countries with Romania having the distribution highly negatively skewed to the left $(-1,2318)$, illustrating the highest risk among all countries that equity funds might have negative extreme values of their returns. The best results were encountered in Hungary, were skewness for equity funds was $-0,593$, suggesting moderate risks of having extreme negative values of returns.

In Hungary skewness was positive for both categories of low risk funds and in Romania only bond funds had a positive value of skewness.

The bond funds and the monetary funds that had a slightly positive skewness of the distribution of returns in Hungary, depict both a situation in which most values are concentrated to the left of the mean returns (mean median was 0,0052 for bond funds and mean median was of 0,0037 for monetary funds) and the extreme values are situated to the right with positive values of returns, indicating lower risks of investment for these fund categories. Similarly in Romania, the bond fund category had the best performance in terms of both returns (median of returns was 0,0057 ) and in terms of risks, as the skewness of the distribution of returns was moderately skewed to the right $(0,674)$.

On overall, it can be stated that Hungary presented the best situation in terms of risks associated with mutual funds, as its negative values of skewness coefficients for high risk fund categories were the lowest among all countries and low risk fund categories had positive values of the skewness coefficients. 


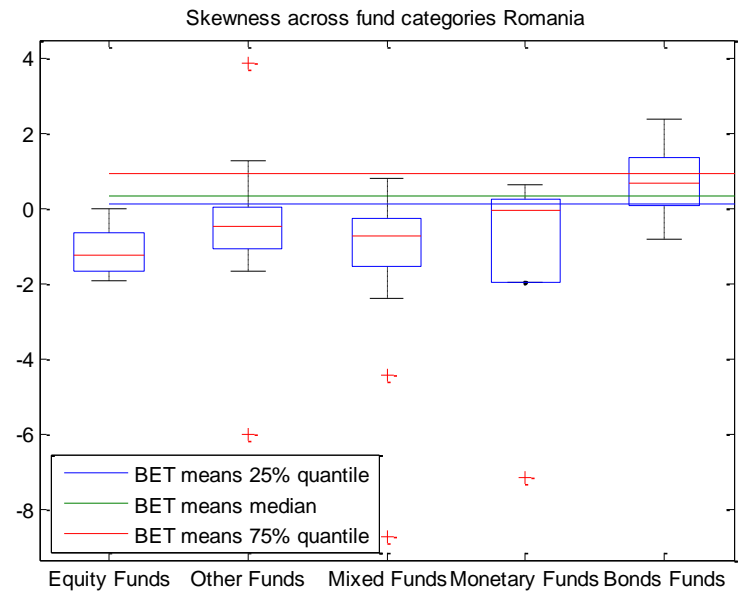

PICBE | 704
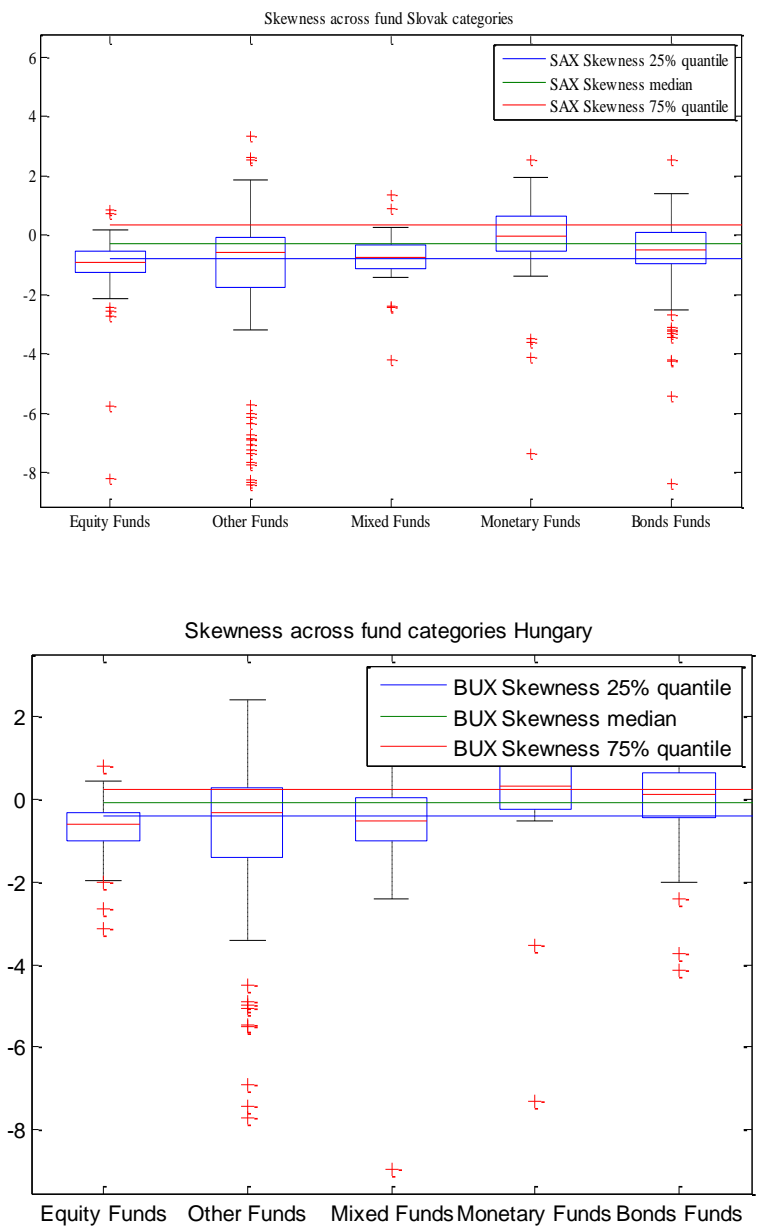

Figure 3. Skewness of returns for mutual funds in Romania (3a), Slovakia (3b) and Hungary (3c)

Source: Authors' research

DOI: 10.2478/picbe-2018-0062, pp. 695-710, ISSN 2558-9652| Proceedings of the $12^{\text {th }}$ International Conference on Business Excellence 2018 


\section{Kurtosis}

The Kurtosis coefficient is used to indicate the level of flatness or peakedness of a distribution by comparison with the normal distribution. It is known that usually investors in capital markets make the decision to invest based on the fact that mean returns are not normally distributed. When the Kurtosis coefficient equals 3 for it is the case of a normal distribution and is known as a mesokurtic distribution. In this case the distribution is bell shaped and has equal tails, neither thin, nor flat. When returns are concentrated at the peak of the distribution, the kurtosis coefficient is above 3 , the distribution is known as a leptokurtic distribution, there are fatter tails and higher risks to have extreme values of returns. When the returns are distributed less at the peak of the distribution, the graphic is flatter, the tails are thinner and there are smaller risks that returns will have extreme values. It is the case we talk about a platykurtic distribution for which the kurtosis coefficient is bellow 3 .

Investors have to consider the returns' kurtosis, as the distribution of values of returns can be used to estimate the risk on potential investment. When data have a platykurtic distribution, a lower kurtosis and thinner tails, returns tend to have less major fluctuations than in a normal distribution and the investment is less risky. In the case of leptokurtic distribution and a higher kurtosis with fatter tails, there are higher chances of having extreme deviations from the expected returns and therefore the investment has higher risks.

In Romania, only the monetary funds had a platykurtic distribution with a kurtosis lower than $3(2,44)$, illustrating lower risks of investments, whereas all the high risk fund categories had leptokurtic distributions with high kurtosis (the median of the kurtosis coefficient over 7), illustrating higher risks of having extreme values. Similarly, in Hungary the only fund category with a platykurtic distribution and lower kurtosis than 3 was the monetary fund category depicting lower risks of investment, whereas the high risk fund categories, they all had leptokurtic distributions (with medians around 4-5) and associated with higher risks of having extreme values. In Slovakia, the monetary fund category registered the lowest kurtosis of all fund categories, but this was 4,85 characteristic to a leptokurtic distribution and associated with higher risks of having extreme values.

The similarity among the three countries is that in all of them, the monetary funds had the lowest risks of displaying extreme values in the studied period. The difference is that Romania presented on overall the highest risks of having mutual funds with extreme values, based on the interpretation of the medians of the kurtosis coefficient, while Hungary presented on overall the lowest risks of having mutual funds with extreme values based on the interpretation of the medians of the kurtosis coefficient.

However, the analysis of figure no. 4 illustrates that even though in Romania the kurtosis coefficients had higher values they were clustered together (there were only a couple of values outside the boxplot for only mixed funds and other funds categories), as opposed to both Hungary and Slovakia, where in spite of lower median values of the kurtosis coefficients, there were numerous values situated outside the boxplots for many fund categories (all fund categories in Slovakia and all fund categories, except monetary funds in Hungary) illustrating again high risks of presenting extreme values. 


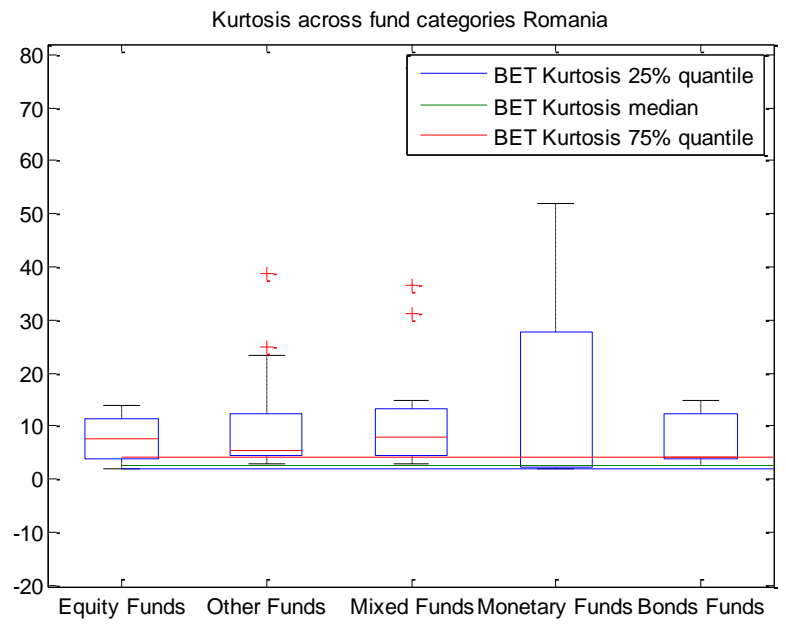

PICBE | 706
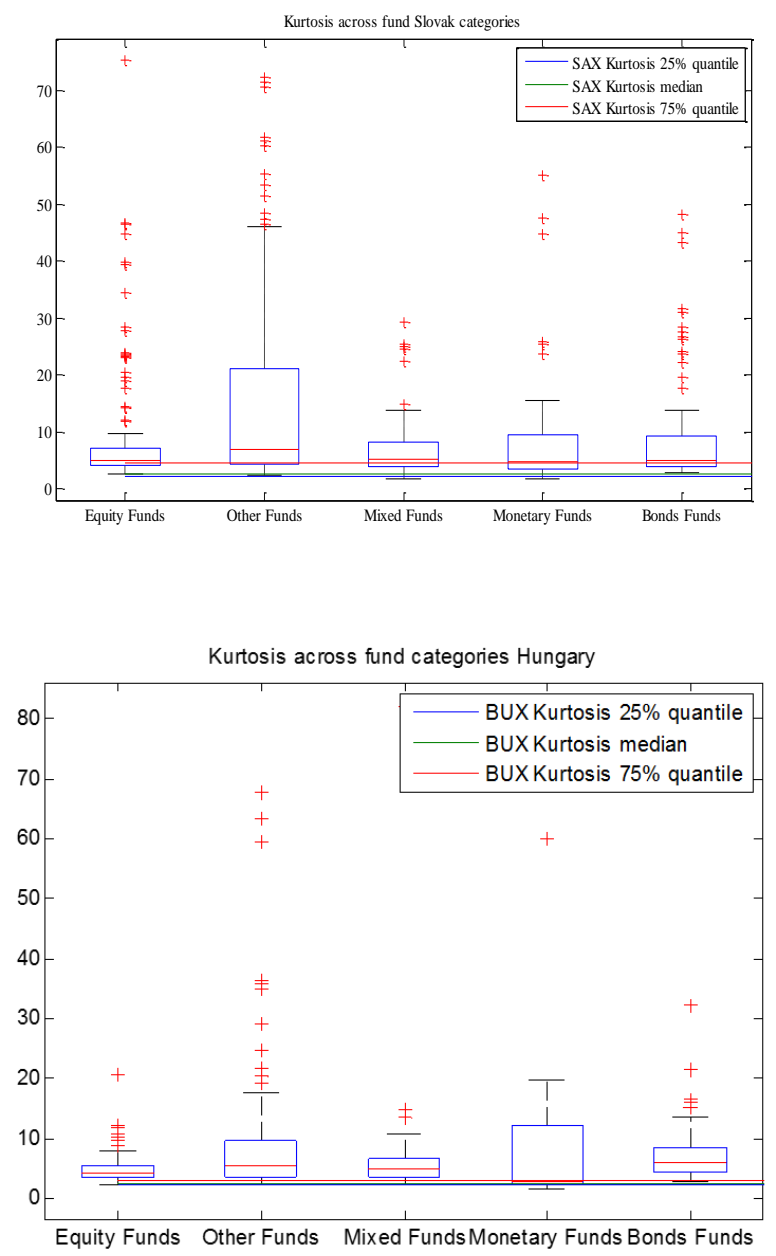

Figure 4. Kurtosis of returns for mutual funds in Romania (4a), Slovakia (4b) and Hungary (4c) 


\section{Conclusion}

The literature that studies financial markets, acknowledges that there are both general characteristics of financial markets worldwide (encouraged by the contagion phenomenon), as well as national characteristics of financial markets, that are influenced by the national investment culture and the influence investment behaviour at country level. The present paper presents an analysis conducted in three emerging financial markets from Central and Eastern Europe, namely Romania, Slovakia and Hungary, where the institutional investment dynamics and the investors' behaviour was studied over a period of 7 years (2007-2014) by looking at 975 mutual funds in total, with monthly observations for each fund included.

The evidence found illustrates that there are both similarities and differences in the evolutions of the mutual funds performances in the three countries, as well as in the investment behaviour. Some of the main conclusions are the following:

- equity funds represent the riskier fund category to invest in all countries analyzed. Analyzing both mean returns and skewness of distribution of returns for equity funds, we can conclude that this funds category re-confirmed its risky character in all three countries, by having negative means (meaning bad performances) and negative skewness of distribution (meaning high risks to have extreme negative values of returns). The kurtosis coefficient also re-confirm the high risks of having extreme values for these fund categories (kurtosis coefficients higher than 3 ) in all three countries.

- in all three countries for all fund categories, the national stock exchange indexes (BET in Romania, BUX in Hungary and SAX in Slovakia) had the median of mean returns lower than the medians of mean returns of the different categories of mutual funds, illustrating on overall higher risks to invest directly to the stock exchange than to invest in mutual funds, as mutual funds offered on average better returns than shares directly bought from the national stock exchanges. We can conclude that diversifying the portfolio can lead to obtaining better returns than the national stock exchange indexes and reduces the risks.

- in all three countries there were high differences between the mean returns of different fund categories, illustrating different performances of those with low risk funds having better performances than the high risk funds.

- in the analyzed period the investments in mutual funds from high risk categories did not manage to offer the investors from any of the countries (Romania, Slovakia, Hungary) better returns than the low risk fund categories. Given the analyzed period that comprises also the global financial crisis period and the fact that some of the national stock exchanges experienced crashes in this period (Romania, Slovakia) there can be explained the less performing results of these fund categories, in comparison with the low risk fund categories: bond funds had the best median mean returns in all three countries. Such a situation is contrary with what would happen in a period of normal economic activity, when high risk fund categories are expected to have better returns.

- as far as the risk of obtaining extreme values of returns when investing in different fund categories, the situation differ from one country to another. In Romania investment in the Bucharest Stock Exchange had lower risk to encounter extreme values than investment in high risk mutual fund categories according to the skewness and this is also confirmed by the median of the kurtosis coefficients. In Hungary the investment in the Budapest Stock 
Exchange presented similar risks of having extreme values as the investment in mutual funds with high risks according to the medians of skewness coefficients, but lower risks of having extreme values according to the median of the kurtosis coefficient (low kurstosis, 2,55, platykurtic distribution). In Slovakia investment in the Bratislava Stock Exchange presented similar risks of having extreme values as the high risk fund categories according to the medians of the skewness coefficient, but lower risks than those according to the kurtosis coefficient (low kurtosis 2,6, platykurtic distribution).

We can conclude that the three countries analyzed presented rather similar than dissimilar trends in terms of both mutual funds evolutions and investors' behaviour, illustrating a similar patterns at regional level for emerging financial markets from Europe. For further research the study can be extended to other countries in the region, so that to identify if the similarities in evolutions and behaviours can be generalized at a larger geographical area.

\section{References}

AAF (Fund Managers' Association from Romania), Retrieved from www.aaf.ro.

Alexakis C., Niarchos N., Patra T. \& Poshakwale S. (2004) The dynamics between stock returns and mutual fund flows: empirical evidence from the Greek market, International Review of Financial Analysis, 14(5), 559-569.

Andrei, A.G., Zaiț, A., Vătămănescu, E.-M., \& Pînzaru, F. (2017). Word of mouth generation and brand communication strategy: findings from an experimental study explored with PLS-SEM. Industrial Management \& Data Systems, 117(1), 478495

BAMOSZ (The Fund Managers' Association from Hungary). Retrieved from http://www.bamosz.hu/.

Barber B. \& Odean T. (2000) Trading is hazardous to your wealth: the common stock investment performance of individual investors, The Journal of Finance, 55 (2), 773806.

Bodie Z., Kane A. \& Marcus A. (2003) Investments, McGraw Hill, Irwin, $5^{\text {th }}$ edition.

Chatfield - Roberts J. (2006) Fundology, The secrets of successful fund investing, Harriman House Publishing.

Cha H. \& Kim J. (2007) Stock Prices and equity mutual fund flows: a macro approach, Working Paper, Oklahoma State University.

Dima A.M. \& Vasilache S.N. (2013). An analysis between the link of emerging markets MNES's reputation and social corporate responsibility, in Leonard, L and Gonzalez Perez, MA (eds.), Principles and Strategies to Balance Ethical, Social and Environmental Concerns with Corporate Requirements, Book Series: Advances in Sustainability and Environmental Justice, 12, 51-66.

Ferreira M.A., Keswani A., Miguel A.F. \& Ramos S.B. (2012). The flow-performance relationship around the world, Journal of Banking\&Finance, 36,1759-1780. 
Fu, R., Navone, M., Pagani, M. \& Pantos, T.D. (2012) The determinants of the convexity in the flow-performance relationship, Journal of Index Investing, 3(2), 81-95, Retrieved

from https://opus.lib.uts.edu.au/handle/10453/22658.

Goetzmann W.B. \& Peles N. (1997) Cognitive dissonance and mutual fund investors, Journal of Finance Research 20(2), 145-158.

Grinblatt M. \& Sheridan T., (1992) The persistence of mutual fund performance, Journal of Finance, 47(5), 1977-1984.

Gruber M.J. (1996). Another puzzle: The growth in actively managed mutual funds. Journal of Finance. 51, 783-810.

Ippolito R.A. (1992). Consumer reaction to measures of poor quality: Evidence from the mutual fund industry, Journal of Law and Economics, 35, 45-70.

Ivkovic Z. \& Weisbenner S. (2009). Individual investor mutual fund flows. Journal of Financial Economics, 92, 223-237.

Li Ma. (2013). Mutual Fund Flows and Performance: A Survey of Empirical Findings, available at https://www.wiwi.huberlin.de/de/professuren/bwl/cofi/research/workingpapers/li-fundflowperformance-2013.pdf, accessed December 2016.

Kim. M.S. (2013). Changes in Mutual Fund Flows and Managerial Incentives, Social Science Research Network, available at http://papers.ssrn.com/sol3/papers.cfm?abstract_id=1573051, accessed December 2016.

Navone M., Pagani M. \& Pantos T.D. (2012). The Determinants of the Convexity in the Flow-Performance Relationship, Journal of Index Investing, 3 (2), 81 - 95, available at https://opus.lib.uts.edu.au/handle/10453/22658, accessed December 2016.

Patel J., Zeckhauser R. \& Hendricks D. (1991) The Rationality Struggle: Illustrations from Finacial Markets, American Economic Review, 81(2), 232-236.

Sapp T. \& Tiwari A. (2004). Does stock return momentum explain the "smart money" effect?. Journal of Finance, 59, 2605-2622.

SASS, (The Fund Managers' Association from Slovakia), Retrieved from http://www.ass.sk/. Sirri E. \& Tufano. P., 1998. Costly search and mutual funds flows. Journal of Finance, 53 (5), 1589-162.

Tudorache F.G., Nicolescu L. and Lupu R. (2015). Evolution of mutual funds in Romania: performances and risks, Romanian Journal of Economic Forecasting, 18(4), 180-197.

Tudorache F.G. and Nicolescu L. (2016). Investor behaviour: The case of mutual funds in Hungary in Brătianu, C., Zbuchea, A., Pînzaru, F., Vătămănescu, E.-M. \& Leon, R.D. (eds.) 2016. Strategica. Opportunities and risks in the contemporary business 
environment. Bucharest: Tritonic, 174-191.

Varga G. and Wengert M. (2010). The Growth and Size of the Brazilian Mutual Fund Industry, available at https://www.researchgate.net/publication/228241214_The_Growth_and_Size _of_the_Brazilian_Mutual_Fund_Industry, accessed Novermber 2016.

PICBE | 710

Varga G. (2011). Mutual Fund Flow and Past Information: Is the Brazilian Investor Smart, available at http://www.anpad.org.br/admin/pdf/FIN568.pdf, accessed November 2016. 